\title{
¿CONTINUIDAD O TRANSFORMACIONES DEL SISTEMA REPRESENTATIVO?
}

\author{
JOSE ASENSI SABATER
}

Universidad de Alicante

Los grandes cambios que están experimentando las organizaciones políticas contemporáneas, transformándose paso a paso en sistemas más amplios de dominación, sitúa en un primer plano la necesidad de una reconsideración de los mecanismos tradicionales de mediación y el papel de los órganos llamados a ejercer la función de legitimación. Es esta una problemática presente hoy en la teoría política y en el Derecho Constitucional, aunque de un modo muy distinto que en el pasado.

Desde la percepción de que asistimos a una "crisis" de los modelos políticos basados en la estructura del Estado y en las fórmulas de Welfare, a la desaparición de barreras ideológicas y en la progresiva interrelación a escala mundial de los espacios económicos, culturales y comunicacionales, la notable paradoja que se produce es que los viajeros esquemas de representación política (representantes, Parlamento, elecciones) se presentan como instituciones que atraviesan una situación de crisis y, al mismo tiempo, contradictoriamente, como uno de los instrumentos más firmes e incontestados en el proceso de recomposición de los sistemas de dominación.

Si por un lado estos esquemas muestran con relativa claridad síntomas de obsolescencia, en forma de desprestigio y desautorización participativa, por otro, la justificación de los sistemas políticos de base representativa no parece representar un problema serio en el contexto de las democracias consolidadas de Occidente, donde los fundamentos jurídicos y los principios representativos, como afirma Hennis, nunca han sido tan poco discutibles como ahora (1).

Al prestigio que ha acompañado tradicionalmente a unos sistema de representación que, en líneas generales, han resistido los más diversos cuestionamientos, algunos de los cuales han sido cuestionamientos frontales, se añade ahora el hecho ejemplar de que esos mismos instrumentos constituyen tal vez el soporte principal sobre el que se trata de basar la reconstrucción de los sistemas políticos de los hasta hace poco llamados Estados de Democracia Popular.

La crítica de las instituciones representativas, en el marco del Estado y en el área cultural europea o europizada, no es, sin embargo, un fenómeno novedoso, sino que puede considerarse consustancial a la evolución de todo el Estado moderno, aunque esa crítica es más aguda en los momentos de crisis; y es justamente en las coyunturas de crisis, cuando los viejos esquemas se ven sustituídos por otros nuevos, si bien de modo aún impreciso, y cuando, por así decirlo, se extiende el sentimiento de inseguridad ante las consecuencias del cambio que toda crisis comporta, es también entonces cuando se producen las respuestas teóricas más contrapuestas. 
Tradicionalmente, las propuestas de reforma de las instituciones representativas, heredadas de la época del liberalismo político, se sitúan, simplificadamente, entre estas dos referencias: la que parte de los propios fundamentos históricos de la representación política, que no es otra que la clásica formulación liberal, postulando se regeneración, y aquélla otra que, en nombre de un nuevo realismo, se plantea una superación definitiva de lo que en estos esquemas pudieran existir todavía de mitificación de la realidad política.

Se podría decir, no obstante, que a pesar de las constantes críticas y revisiones a que ha estado sometido el modelo liberal de representación, como ha recordado Virga, no ha habido en los últimos cincuenta años un verdadero debate que explícitamente haya abordado los cambios que se han ido introduciendo en el modelo representativo heredado de esa tradición liberal-burguesa, pese a que podían identificarse bastantes características que diferenciaban muy claramente los aspectos formales del sistema político y el sistema de representación política de las sociedades capitalistas de los años inmediatamente anteriores y posteriores a la Primera Guerra Mundial con respecto a los existentes en las sociedades anteriores (2).

Estas diferencias, en lo esencial, se referían a aspectos tales como la virtual universalización del sufragio universal, la presencia de partidos de masas organizados, el desarrollo de los organizaciones permanentes de representación de intereses específicos con un nuevo papel institucional, o a las nuevas formas que comenzaba a adoptar la producción legislativa que, a su vez, reflejaba un cambio gradual desde una concepción universalista de las leyes asociada a la edad del liberalismo clásico, hacia una mayor especificidad en el contenido de las leyes y una paulatina delegación del poder en organismos administrativos (3).

Ahora bien, uno de los aspectos significativos que singularizan la crisis actual de los esquemas representativos que presenta el Estado de Bienestar, es el hecho de que se encuentran inexorablemente presionados por las nuevas complejidades sociales, por sectores y grupos sociales, minorías, y grupos que no encuentran en dichos esquemas cauces apropiados o posibilidades de expresión; tal vez podría explicarse esta situación diciendo que la complejidad y fragmentación que presentan los diferentes movimientos sociales es hasta cierto punto incompatible con el proceso hacia la unidad y homogeneidad que de suyo implica el sistema representativo.

Se trata, pues, de una crisis, pero de una crisis que parece afectar a determinados supuestos estructurales en el funcionamiento de los sistemas representativos y que, afecta, si bien no a la totalidad de sus funciones, sí desde luego, y de modo significativo, a algunas de ellas.

No parece, por de pronto, que estemos ante una situación similar a la crisis que padeció el sistema representativo de raiz liberal en los años veinte y treinta: se trataba entonces, como es sabido, de sustituir los clásicos mecanismos liberales de representación individualista y la expresión de éstos en las instituciones parlamentarias, por otros de naturaleza organicista; independientemente de otros fatores históricos e ideológicos, no fue ajena a las críticas radicales procedentes del campo conservador, como demuestran los escritos de Schmitt y la realidad política de la época, la bús- 
queda de un sistema de representación que asegurara la viabilidad de una sociedad sometida a un intenso proceso de industrialización y amenazada por una grave pérdida de identidad (4).

Por el contrario las críticas al sistema representativo que se formulan hoy -en la medida en que, como decíamos, y salvo propuestas residuales, no comprometen las líneas maestras del sistema liberal-democrático, pues sólo este sistema se presenta como garante del soporte legitimador de los sistemas de dominación actuales -tienen un tono distinto a las críticas radicales que se produjeron en Europa en los años treinta: no se presentan, en primer término, como alternativas institucionales; no pretenden una modificación profunda de las reglas principales que regulan el instituto representativo; son críticas, por último, que envuelven el problema de la representación en un discurso más general, fuertemente teñido de componentes neoideológicos, es decir, se conectan directamente con una formas de discurso que, desde pretensiones invitablemente hegemónicas, se presentan como discursos sobre la "sociedad".

Ello no quiere decir en modo alguno que no puedan surgir, o no puedan estar surgiendo, alternativas representativas en las que, de nuevo, se exarcebe la idea identidad nacional, la armonía de la concepción corporativa del mundo o, incluso, el componente de la adscripción religiosa frente al sistema tradicional de representación individual y de organizaciones partidarias; bastará señalar por el momento que estas referencias no parecen estar incluídas entre los principales elementos legitimadores que alimentan los nuevos procesos de dominación; es más, como decíamos, tras el fracaso de los sistemas políticos de inspiración marxista, resplandece aún en mayor medida la solidez de los fundamentos liberal-democráticos de los sistemas representativos, al servir no sólo como instrumento -con toda la carga de evidencia práctica que ello supone- para la recomposición de las organizaciones politicas de estos países, sino como uno de los principales estándares que se exhiben como necesarios para dar credibilidad a la configuración de un pretendido $-\mathrm{y}$, una vez más, "nuevo", orden mundial.

Es por ello que vamos a referirnos a algunos aspectos del debate que se está produciendo en torno a la "crisis" de los sistemas representativos, es decir, a la inadecuación, que no "quiebra", de los instrumentos tradicionales de representación ante lo que denominábamos el proceso creciente de complejidad y fragmentación social de las sociedades actuales, comenzando por señalar someramente los polos más extremos en que se sitúan las alternativas de reforma, pues su delimitación, aún a riesgo de resultar simplificadora y reduccionista, permite contemplar mejor el núcleo de la problemática.

\section{ENTRE EL ARCAISMO Y EL FUTURISMO.}

Tanto hoy, pues, como en el pasado, las respuestas que provienen del campo de la teoría política, ante las deficiencias que presentan las instituciones representativas (pues no hay que olvidar que la idea de que el Estado sufre una constante "crisis de representación", es una idea antigua y ha venido ocupando un lugar central en la reflexión teórica) (5) suelen encontrarse ante una encrucijada con dos polos de fuga opuestos. 
De una parte, se presentan las propuestas arcaizantes, esto es, aquellas que tratan de volver la mirada al pasado, buscando en él no solo una fuente de inspiración sino, sobre todo, el modo de obtener una base segura desde la abordar las complejidades del presente; de otra, la tentación que podríamos considerar como futurista, por emplear también aquí el término acuñado en otro orden de cosas por Toynbee, cuya lógica conduce ante todo a propiciar un cambio radical del estado de cosas existente con una finalidad explícitamente revolucionaria (6).

\section{a) La orientación arcaizante.}

La orientación arcaizante significa, en cierto modo, una vuelta atrás, como una tentativa para volver a uno de aquellos estados más felices que, en los tiempos revueltos, se deploran más agudamente -y quizás se idealizan más ahistóricamentecuando más se alejan. ("iOh, cuanto deseo volver atrás/ y recorrer otra vez la antigua senda!/ para poder alcanzar una vez más aquella llanura/donde dejé primero mi gloriosa comitiva.../algunos hombres aman marchar hacia adelante/pero yo me movería andando hacia atrás"., dirá el poeta inglés Henri Vaughan).

Para algunos, la reforma del Parlamento y del papel de los representantes se ha de orientar hacia el objetivo de la recuperación de estas instituciones en su forma más pura; una forma perdida tal vez en algún punto de su recorrido histórico dificil de precisar, pero donde -se afirma- podría reconocerse su entidad en cuanto que instituciónes que llegaron a expresar una voluntad política dirigida al bien común y servida por una clase de representantes adornados de un hondo sentido de la responsabilidad y seguros en su independencia de cualquier tipo de presiòn.

Sabemos hoy, sin embargo, con relativa claridad, que detrás de esta idea regeneracionista no se esconde en el mejor de los casos sino una ilusión. No sería necesario insistir en que, desde los tiempos de Dicey, no ha cesado el debate sobre la existencia o no de una era específicamente liberal. Los artículos profundamente revisionistas de Brenner (6), entre otros, sobre el laissez faire y el intervencionismo estatal, han supuesto un refuerzo considerable para la tesis, contrastada una y otra vez, de que no ha exitido nunca una edad de oro del "laissez faire", sino más bien una determinada construcción doctrinal que ha disfrutado de considerable influencia.

Sin embargo, como se desprende claramente de las perspectivas neoliberales actuales, la reconstrucción del modelo político que se propone, no pasa por la vigorización del Parlamento o de las instituciones representativas sobre la base de un desarrollo de sus contenidos democráticos, sino, por el contrario, por un sistema basado en la autorresponsabilidad individual y regulado por normas simples que aseguren la libertad de mercado.

b) La tentación futurista.

Por el contrario, la perspectiva futurista, más arriesgada en su formulación, suele contemplar, en general, la disolución forzosa de cuerpos, corporaciones, clases y partidos. Se parte aquí de una crítica radical de las instituciones existentes para pasar a imaginarse un orden nuevo y, en ocasiones, autotrascendente.

Si en otras épocas representó una actitud futurista la postulación de la igualdad 
material entre los hombres, el rechazo a la sociedad burguesa y su expresión parlamentaria y su sustitución por instrumentos participativos basados en la identidad espitirual entre gobernantes y gobernados, o bien lo fue asímismo la propuesta de liquidación de las clases y sus partidos organizados en beneficio de un sistema orgánico-naturalista donde presuntamente se armonizaban los intereses al unirse en el organismo social, hoy, al haberse agotado en cierto modo el ciclo que estas ideologías abrieron, la respuesta futurista viene dada ante todo por una extrapolación de las posibilidades que ofrece la revolución tecnológica en el campo de las organizaciones políticas.

La imagen más extrema de esta orientación es, tal vez, la de la superación de las viejas instituciones parlamentarias y partidiarias, por un espacio continuo de decisiones señalizadas a través de los ordenadores personales (7).

\section{PLURALIDAD SOCIAL Y HOMOGENEIDAD REPRESENTATIVA.}

En medio de estas dos extremas posiciones se encuntra un amplio panorama de propuestas de reforma del sistema representativo que, en lo esencial, se ubican en el respecto a las reglas básicas del sistema democrático-liberal.

La apertura de los sistemas políticos a espacios más amplios, con la debilitación de los vinculos estatales y la pérdida de significado de la soberanía nacional, es una de las consecuencias, y no la principal, de la internacionalización del modo de producción capitalista un una nueva fase de desarrollo y transformación de las sociedades (8). Es este el terreno, a nuestro parecer, donde debiera situarse un debate fructífero sobre los problemas actuales que conllevan los mecanismos de representación y de legitimación políticas.

Por ello parece obligado partir del supuesto de que una buena parte de los grandes problemas que afectan a la organizaciones políticas es este fin de siglo, en la medida en que suponen obstáculos para la realización de los objetivos democráticos, no tienen su solución, si es que existe una solución que dé forma definitiva a las exigencias de participación y control de los ciudadanos en las decisiones que les acectan, en la escala del Estado, del mismo modo que el problema reside ahora, en lo esencial, en cómo establecer garantías para que las decisiones que hayan de adoptarse, y que de hecho se vienen adoptando ya, en esa otra escala supraestatal, estén sometidas a mecanismos de responsabilidad pública y existan cauces adecados de información, participación y control.

Se han alterado, pues, sustancialmente los supuestos sobre los que se sustentaba anteriormente el esquema representativo y, en consecuencia, los fundamentos de su propia legitimación. Pero esta traslación de la problemática representativa hacia formas de dominación más generales, sin embargo, no va acompañada de mecanismos eficaces de control democrático del proceso mismo; quedan en pie los problemas derivados de la adecuación del proceso político-democrático a los sistemas de representación imperantes todavía hoy en el constitucionalismo occidental.

Del mismo modo que muchas de las estructuras políticas, nacidas de la transformación democrática del antiguo esquema liberal, han persistido hasta este fin de 
siglo, y se encuentran ahora sometidas a un intenso proceso de adaptación, así ocurre con los esquemas representativos; el mundo que aflora tras la crisis de los sistemas políticos del Este de Europa, las presiones sociales que delatan, cada vez con mayor intensidad, que las bases sociales de los antiguos estados-naciones sólo pueden considerarse homogéneas madiante un mecanismo de perversión simbólica de la realidad, la fragmentación interna de las sociedades desarrolladas y las distintas posiciones que en ellas ocupan los individuos, todo ello, pone de manifiesto las dificultades de los sistemas representativos para conseguir expresar, por vía legitimación, no solo la pluralidad de la sociedad y la coexistencia en ella de los valores más diversos, (9) sino la propia capacidad de integración en el sistema político, al que aspiró, muy sustancialmente, el mecanismo representativo ideado desde las revoluciones liberales.

De un lado pues, nos encontramos con una extremada fragmentación y pluralidad de lo social que se diversifica y recompone en espacios políticos muy diversos (10); de otro, un sistema que legitima la organización política estatal, a través de mecanismos representativos pensados para funcionar -o, incluso, para contribuir a formar- en sociedades homogéneas, tanto en lo referido a los intereses prioritarios que el propio sistema representativo estaba llamado a expresar, como en lo referido a su funcionalidad acorde con un mundo valorativo relativamente exclusivo.

\section{REPRESENTACION Y LEGITIMACION}

Si este planteamiento, mínimamente esbozado aquí, permitiera una aproximación al centro del problema, sería necesario sin embargo, y antes de proceder al exámen de los elementos de transformación y continuidad de la institución a la luz de la modificación de los contextos de los que opera, centrar la atención en un punto donde los mecanismos representativos se implican en la problemática más general que presentan las organizaciones políticas contemporáneas, esto es, la problemática de la legitimación.

Se ha aludido, con el propósito de explicar la crisis de representación en la que presuntamente nos encontramos, a que ésta no es sino un aspecto de una problemática más global encuadrada en torno a la llamada crisis del Estado Social y más específicamente a la crisis de legitimación vinculada a aquél (11).

En su formulación más genral, se alude a que el proceso de crisis de legitimación se plantea inevitablemente cuando aumenta la desproporción entre las demandas que se plantean al sistema, cada vez mayores en número y heterogeneidad, y la capacidad limitada que tiene el sistema público para satisfacerlas. La lógica consecuencia, entre otras, de esta contradicción es el deterioro de la institución representativa que es, entre las instituciones del Estado, la que aporta mayor dosis de legitimación al sistema.

Asistiríamos, pues, a una crisis de legitimación del Parlamento y a un cuestionamiento desde todos las ángulos del papel de los representantes políticos (12). Ahora bien, no se trata, desde esta perspectiva, de anunciar una nueva versión de la crisis de la institución parlamentaria, como consecuencia de su pérdida de influen- 
cia relativa respecto a otros poderes del Estado y otras instancias públicas o semipúblicas. Se trata, como ha indicado Labriola (13), por el contrario, y como nuevo dato característico de la crisis del Welfare State, de un debilitamiento general de las instituciones de la democracia representativa, que afecta de un modo similar y solidario al Parlamento, al Gobierno y a la Administración y que, más allá, afecta también al funcionamiento tradicional del sistema de Partidos Políticos.

No estaríamos, pues, ante el supuesto de tratar de recuperar para el Parlamento un poder que le ha sido arrebatado por el Gobierno, pues este poder o autoridad ya no está depositado en aquél sino que ha ido a parar a otros ámbitos subinstitucionales, sino ante el problema de cómo restituir la legitimidad al conjunto de las instituciones públicas.

Sin embargo, esta visión que transfiere la problemática del Parlamento y la representación a la existencia de una crisis profunda de legitimación del sistema del capitalismo avanzado o desarrollado, aunque contiene un fondo de verdad, parece en ciertos aspectos superada, o la menos, en trance de haber entrado en una nueva fase: ampliamente difundida en la década de los años setenta principalmente por $\mathrm{C}$. Offe, J. Habermas y O'connor, partía de la afirmación de que las contradicciones internas del Estado Social terminarían por explotar a darían lugar a nuevas formas de relación entre el Estado y la Sociedad.

Pero los procesos político-sociales de la década de los años ochenta se han separado notablemente de las previsiones en este punto y hasta la propia terminología de crisis de legitimación ha dejado de ser utilizada por estos autores (14). No se ha producido, como demuestran todas las evidencias, al menos con caracteres de rotundidad, una crisis de legitimación definitiva, aunque han cambiado las bases sociopolíticas y estruturales de las sociedades avanzadas y ello de tal modo que, paradógicamente, la penuria y del desempleo producidos por la crisis económica no han erosionado, sino al contrario, han fortalecido en muchos aspectos el reformismo neocapitalista y la democracia parlamentaria.

Por ello, si la problemática de la legitimación ha de subsistir, y a nosotros así nos lo parece, será también aquí como referencia a procesos de dominación más generales. A partir de la internacionalización de los problemas políticos y la evidente inevitabilidad de la transición hacia formas de mediación más complejas, hemos entrado en una nueva época de grandes espacios inperiales para los que, hasta ahora, como ha señalado Hennis, no se ha conseguido desarrollar en la Historia una forma legitimable de dominación (15).

Las consecuencias de todo ello en el orden representativo, que como tales pueden apreciarse en los mecanismos jurídicos y en la institucionalización de las reglas constitucionales, son relativamente conocidas. En síntesis, puede decirse que el problema principal es el siguiente: Por un lado se constata la persitencia institucional de las reglas representativas, consagradas constitucionalmente, que en lo esencial, corresponden a reglas derivadas del modelo liberal-burgués de representación; por otro, se constata la existencia de nuevos espacios político-representativos como consecuencia de las necesidades de los procesos de dominación contemporáneos que 
afectan ahora tanto a las funciónes subjetivas de los representantes políticos como a las funciónes objetivas del sistema representativo en sí mismo considerado.

\section{REPRESENTACION Y UNIDAD POLITICA.}

Hay en la tradición filosófica occidental la tendencia a explicar la política con conceptos que provocan una concepción unitaria de la sociedad. Tal vez esa una tendencia dificilmente evitable. Después de todo el viejo discurso de Hobbes se introduce una y otra vez, y más si cabe cuando se trata de teorizar sobre los procesos de dominación.

El problema se plantea cuando esas conceptualizaciones ya no reflejan las características esenciales de los procesos políticos vigentes o no tienen en cuenta los estados de diversificación que se introducen en las sociedades complejas de nuestros días.

Si el desarrollo de los sistemas representativos de raiz francesa ha ido unido al proceso de desarrollo de esa forma de Estado, desde la idea de unidad de la Nación expresada por o en el Parlamento, es de todo punto natural que, en su origen, el establecimiento de instrumentos de representación política, lejos de suponer un modo de llevar al centro del sistema la voz de los intereses concretos o parciales de un grupo o estamento, esté presidio inexorablemente por la lógica del conjunto, de la totalidad.

En el mundo estamental, al asegurar el Soberano la unidad política misma, los diversos intereses y rangos concretos tienen acceso al centro del sistema, si bien no con carácter decisivo. Son, por otro lado, intereses claramente identificados porque estaban definidos, como ha señalado Pizzorno, por la propia estructura social (16); a medida que los estamentos fueron perdiendo su poder en favor de la monarquía absoluta, los criterios sufrieron un cambio sustancial: con la sustitución del soberano real por el Soberano Nacional, las partes o los grupos representados ahora en el parlamento, no podían, por propia lógica, querer otra cosa que el interés de la Nación.

No sólo se partirá de una voluntad única que reside en aquélla, sino que el criterio estamental de identificación de intereses fue sustituida por el criterio geográfico. Tal es, en esencia, el supuesto político y la consecuencia doctrinal que se plantea con la revoluciónes liberales.

Lo característico del pensamiento liberal-burgués fue considerar que la sociedad era capaz de convertir los egoísmos privados en intereses comunes, y esos intereses comunes no eran sino expresión de los propios "intereses nacionales" (17).

A la idea de Nación como sujeto de la Soberanía, en lugar de la vieja noción de la Soberanía del monarca, corresponde ahora una determinada concepción jurídica, en virtud de la cual, y en su clásica formulación, no son los ciudadanos los directamente representados en el sistema político sino la Nación misma que, si bien no puede decidir por sí sola, puede sin embargo actuar por medio de representantes (18). El poder, como se ha dicho expresivamente, cambió de aspecto, no de naturaleza, en 1789 (19). 
Ciertamente que el principio representativo, entendido ahora ya no como "representación ante el poder", a la vieja manera del Parlamento Inglés, sino como exigencia de que el poder político mismo fuera "representativo" originó, como se sabe, un conjunto de extraordinarias consecuencias: alimentó una nueva cultura política, generó una serie de nuevos mecanismos constitucionales, inspiró una nueva forma de entender las relaciones entre Poder y la Sociedad mediante el establecimiento de instituciones de control, contribuyó a deslegitimar en cierta medida la abstracta razón de Estado, y permitió introducir en el Estado, progresivamente, a nuevos grupos sociales que fueron conquistando madurez política y fuerza organizatoria (20). Pero nunca como ahora el principio de representación había dotado al Estado del fundamento ideológico y de los mecanismos legales que permitieran desarrollar todas sus potencialidades.

Sin embargo, desde la ruptura de los supuestos representativos heredados de las revoluciones burguesas, cuyo modelo más conspicuo viene dado por la Contitución francesa de 1791, que se produjo en el transcurso del siglo XIX como consecuencia del movimiento de democratización, con la aparición de la delimitación de clases y los partidos políticos de masas, el fundamento de la unidad (unidad social en torno al tercer estado, unidad espiritual expresada en el ideal de la Nación, unidad política en el Estado) sobre la que descansaba el esquema representativo burgués quedó roto definitivamente.

Como ha escrito De Vega (21), la imagen de la sociedad como un todo homogéneo donde existen intereses comunes se sustituye por una versión hobbesiana de confrontación y de lucha entre intereses irreconciliables:

"... cuando la idea de pueblo y de Nación como unidad se rompe, y cuando surgen intereses sociales antagónicos, no hay ninguna razón para privar a ningún grupo del derecho de sufragio en nombre de una unidad o de un interés común que no existe...".

La fragmentación de la unidad política, sobre la base de una homogeneización ideal de la sociedad, y bajo el predominio de valores burgueses, no sólo se ve potenciada por la aparición de los partidos de clase y la escisión que éstos expresan de una sociedad dividida social e ideológicamente, sino que, más adelante, se ve confirmada por el desarrollo de sociedades que, ex novo, como la americana, se fundan en valores no homogéneos sino fuertemente pluralizados por todo un conjunto de factores (religiosos, lingüísticos, étnicos, territoriales, de diversidad de intereses) que inauguran un modelo representativo bastante diferente del desarrollado a partir de las clásicas definiciones difundidas a partir de los postulados representativos del Estado -Nación que vieron la luz en la época de la Gran Revolución.

La fragmentación de la unidad de sociedad, como un todo homogéneo que, como tal, puede ser representada es, desde entonces, un proceso que no se ha interrumpido, sino que se ha extendido e intensificado. Los supuestos desde los que se puede hablar del Estado Social, como modelo político más o menos difundido a partir de la segunda guerra mundial, partía también de una diversificación y pluralidad de los diferentes intereses sociales, sobre la base de un compromiso, pero que alte- 
raba sustancialmente los mecanismos tradicionales de representación y mediación en beneficio de prácticas corporativas comunmente admitidas y circuitos de representación política paralelos o complementarios a los consagrados en las normas constitucionales (22).

Formalmente, sin embargo, la vocación de unidad que el sistema del representación comporta obliga, constantemente, a recomponer el sentido de esta función objetiva y ello tanto más cuanto la propia fragmentación de los espacios sociales y la pluralidad de identificaciones hacen más frágil y compleja la toma de decisiones. En este punto, diversificación social y de intereses, gobernabilidad y decisión autoritaria del Estado y sistema de representación se implican.

Tan decisiva resulta da idea de hacer residir en una matriz única o unitaria el fundamento representativo del Estado moderno que los intentos por reconstruirla no han cesado hasta nuestros días. Ya desde Hobbes, es la unidad del mandatario, no la unidad de los representantes "lo que hace a la persona una". Este fundamento, firmemente anclado en la noción de "unidad de lo representado", se presentará a lo largo de la evolución de la doctrina política bajo diferentes versiones: "la razón general del todo", proclamada por Burke, la idea del pueblo "como un todo unificado por un interés", expuesta por Bentham y los utilitaristas, la versión francesa de la Soberanía Nacional, elaborada por Sieyés, donde la Nación se presenta como "un todo unido", o bien, más adelante, en las formulaciones de Schmitt, Leibholz o Triepel (el pueblo no puede ser representado en su unidad natural, aunque sí en su unidad política), Bluntschi o Klüber, para quienes el moderno sistema representativo se engendra en al unidad del pueblo considerdo en su conjunto, en una línea que llega hasta Heller, para quien el concepto de representación es fundamental en la constitución jurídica del Estado porque es el instrumento que permite la reducción de la pluralidad social y la conversión de ésta en la unidad de acción y decisión.

En definitiva, el pensamiento del sistema representativo en la democracia es, ni más ni menos, como recuerda Leibholz, el de asegurar de este modo la soberanía del pueblo, como unidad, sobre el pueblo como multiplicidad, como muchedumbre o multitud.

En contraste con estos esfuerzos, que se derivan de la propia lógica que preside el supuesto representativo, la Historia Política de la Europa Occidental desde el último tercio del Siglo pasado hasta la época posterior a la Segunda Guerra Mundial muestra con una gran claridad cómo los conflictos de clase se han expresado muchas veces al margen de los sistemas de representación, mientras que en otras ocasiones se han canalizado por medio de éstos, pero, en todo caso, muestran la descomposición de esta ideología esencialista basada en el supuesto de la existencia de un ideal común en una sociedad de clases, intereses y grupos diferenciados. La evidencia de la naturaleza escindida y contradictoria de la sociedad sobre la que opera el modelo de representación liberal, va a afectar de modo inexoreble a su construcción jurídica: porque sólo desde el supuesto de la unidad de lo representado es posible un determinado tratamiento jurídico, cuando aquél desaparece, el mecanismo representativo se revela, según ya afirmara Kelsen, como una ficción. 
El intento de reconstruir un espacio unitario desde el que fundamentar una teoría de la representación vuelve a reproducirse a partir de los años cincuenta: No se trata sólo de la tendencia "arcaizante" que puede representar, por ejemplo, Hayeck y que da pie, en nombre de la libertad individual, al planteamiento neoconservador dominante en los últimos años, sino también se trata ahora de formular la reunificación de "lo social", no ya mediante la apelación a conceptos esencialistas, como la nación o el pueblo, sino mediante el recurso de partir de la idea de una sociedad conflictiva y pluralista, con intereses diversificados y contradictorios, pero en una suerte de equilibrio y estabilidad basados en el "acuerdo" entre los diferentes intereses sociales.

\section{UNIDAD, LEGITIMACION, RESPONSABILIDAD.}

Estas dos funciones del sistema representativo -la referencia a la unidad y el soporte legitimador que otorga al sistema político- se completan con una tercera función, más oculta, referida al principio de responsabilidad de los representantes, esto es, al hecho de que éstos y las instancias en que se integran hayan de algún modo que responder de su cualidad de tales.

El modo de hacer posible esta responsabilidad en la actuación de los representantes, las articulaciones, en suma, entre las dos instancias de la relación representativa -representados y representantes- ha seguido modelos muy variados; desde un modo de responsabilidad abstracta, como en el discurso de Sièyes, donde los representantes lo son de la Nación, hasta un modo de responsabilidad concreta, como en el supuesto de que los representantes responden de modo directo ante quienes los han elegido, como en el discurso rousseauniano; desde un modelo representativo que tiende a asegurar la autoridad de la decisión política, hasta un modelo que postula la legitimidad previa de la más amplia representación para validar la decisión misma; modelos, en fin que, en sus extremos, pueden suponer desde la disolución del caracter ficticio de la representación respecto a lo representado mediante una total transparencia de los medios, hasta la opacidad total entre los representantes y los representados mediante una ficción estrictamente literal del vínculo que los une.

Ambos extremos no son situaciones imposibles y de hecho se han dado en la praxis de las instituciones representativas. Sin embargo, lo que la evolución de las instituciones representativas revela, a partir de la transformación democrática de los supuestos liberales tradicionales, es precisamente la introducción de mecanismos relacionales, es decir, mecanismos que hacen relativamente operativas las relaciones entre representantes y representados y permiten hablar de un elemento de responsabilidad en la actuación de aquéllos y de mecanismos de control en la esfera de las posibilidades de éstos.

Instituciones tales como las elecciones periódicas y las legislaturas de corta duración, la extensión del sufragio universal, la organización del pluralismo en torno de los partidos políticos, las instituciones complementarias de la democracia directa, los mecanismos interelectorales de control, el papel de los medios de comunicación y la fortaleza de la opinión pública, se han imbricado con las reglas clási- 
cas de la representación política componiendo un complejo desigual, pero introduciendo una estructura relacional que justifica en cierto modo el hablar de un modelo de democracia representativa.

En lo sustancial es este el modelo que ha quedado en pie, una vez invalidados tanto lo sistemas autoritarios que se refieren a un sujeto abstracto de la representación, como los que reivindican un maximun de legitimidad sólo alcanzable mediante la desaparición de toda representación en beneficio de la democracia directa. $\mathrm{Si}$ algo deja claro la evolución de las instituciones democráticas a lo largo de más de siglo y medio es, precisamente, de un lado, el desvelamiento progresivo de los sujetos colectivos y esencialistas, la ruptura de las referencias abstractas y, de otro, la inviabilidad del gobierno directo no solo por su imposibilidad técnica en el orden organizativo, sino por haber quebrado el supuesto de homogeneidad de intereses y el telos ideológico en que se sustenta una concepción del mundo que reclama este principio de organización del poder.

De este modo, los supuestos relacionales de la democracia representativa, aún no habiendo desarrollado todas sus potencialidades, no se refieren a un modelo que suponga un punto intermedio $-\mathrm{y}$ por tanto no dotado de entidad propia- entre los "modelos de decisión" y "los modelos de identidad", sino, a nuestro modo de ver, como el resultado no lineal, sino contradictorio, de prácticas articulatorias entre intereses diversos, pero que, en conjunto, han premitido avanzar en la expresión democrática de esos mismos intereses.

\section{Continuidad y transformación de los supuestos representativos.}

La crisis de la representación política afecta, entonces, a estos tres elementos funcionales que forman la estructura de las instituciones representativas. La crisis de representación es, efectivamente, una crisis de legitimación, en la medida en que la institución no logra obtener el reconocimiento de que la instancia representativa es portadora de intereses concretos y determinados, los cuales puedan corresponderse a las exigencia y en el contexto de una sociedad cada vez más fragmentada; al tiempo, es también una crisis de gobernabilidad, porque por mediación de la representación política no se consigue obtener el consenso suficiente para fundamentar el respecto a la decisión política, puesto que, además, una buena parte de las decisiones políticas de importancia se escapan a las posibilidades de decisión que puedan tener lugar en el orden monocéntrico del Estado.

Es por último, también, una crisis de la estructura de relaciones, mediadas por las instituciones de origen democrático, entre representantes y representados, en el orden de las responsabilidades y los controles respectivos: en este sentido, el cuestionamiento del papel de los partidos políticos, el apartamiento de la participación electoral, el uso pervertido de la apelación al "pueblo", la aparición de movimientos y actitudes al margen de los circuitos democráticos, muestran con toda evidencia el "desbordamiento de lo social" en relación con los cuadros relacionales y organizados de la sociedad.

Las trasformaciones del modelo representativo proceden de una profunda modificación de la realidad social y política de nuestros días. La tentación de resolver 
estas contraposiciones mediante la construcción de modelos fuertemente ideologizados, con pretensiones hegemónicas, para encubrir la carencia de legitimidad y favorecer un orden de decisiones determinado, se hace entonces evidente. La tentación de volver, por el contrario, hacia planteamientos esencialistas, proponiendo nuevas identificaciones colectivas estan bién evidente.representativos ha de paser por una potenciación de sus posibilidades democráticas. La ambigüedad que ha caracterizado a este modelo -que está por otro lado presente a lo largo de su construcción histórica- permite, como ha recordado Agnolli, su utilización como instrumento de progreso y ello aún en mayor medida si se incrementan sus posibilidades relacionales. Por otro lado, el resquebrajamiento de estas instituciones arrastraría inevitablemente los supuestos legitimadores que contiene y el compromiso social de fondo en el que se implica.

Esta dirección marca un programa de renovación de la democracia, una resituación del papel de los partidos políticos, mecanismos más efectivos de ixgencia de responsabilidad y la extensión de los supuestos representativos a otras esferas de la vida social y económica, dando sentido, al fin, al profundo carácter material que la noción de representación potencialmente encierra.

\section{NOTAS}

1.- Wilhelm Hennis, "Legitimät-zu einer kategorie der bürgerlichen Gessellschaft", Duisburg, 1975.

2.- Virga, "Il partito nell'ordinamento giuridico", Milán, 1948. Como es motorio, la problemática de las transformaciones de la democracia ha dado lugar a una amplísima literatura jurídica (Ambrosini, Hula, Adler, Morstein, Marx, Radbruch, Strale, Kaufman) que, desde diferentes perspectivas, han hablado de la existencia de una verdadera mutanción constitucional.

3.- Lowi, Th., "The end of liberalism", N. Y. Norton, 1969. -De Cabo, C. "La crisis del Estado Social", Barcelona, 1986. Para de Cabo, ya durante la etapa del Estado Social se había registrado la crisis de las normas generales y abstractas: "la Ley cuyo sentido en el Estado de Derecho era el de ser garantía de los procesos sociales pasó a ser reguladora específica de los mismos. Dejó de servir como factor de integración social. Si en el Estado Liberal-escribe De Cabo- la ley era el correlato de unas representaciones que se hacían en base a lo que era común a los ciudadanos (salvaguardando lo que les diferenciaba: es decir, la propiedad) y de ahí su generalidad, en el Estado Social la norma se hace instrumento del Estado para la intervención en situaciones específicas". De ahí que se eluda la utilización de la ley a través del mecanismo de la legislación delegada en el ejecutivo, la potenciación de la potestad reglametaria y se produzca el desplazamiento progresivo de competencias a organismos supranacionales. En este último caso, la internacionalización jurídica sigue a la internacionalización del capital.

4.- Amato, G. "forma di estato e forma di governo", en Manuale di Diritto Pubblico, a cura de G. Amato e A. Barbera, Bologna, 1984.

5.- Toynbee, Estudio de la Historia, II, 135 y ss., Barcelona 1984.

6.- Brenner, "Journal of Economic History", 8, 1948. -Un apunte sobre la contrucción del mito de la edad de oro del liberalismo, sumamente interesante, puede encontrarse en Maier, Charles S." Los vínculos ficticio...de la riqueza y de la ley" :sobre la teoría y la práctica de la representación de los intereses, en "La organización de los grupos de interés en Europa Occidental", M. 1988. Para Maier, la agudización de los conflictos de clase desde principios del siglo $\mathrm{XX}$, hizo que los liberales apoyaran y casi siempre idealizaran los partidos de notables de 
mediados del siglo XIX en contraste con la zafiedad y la demagogia que tribuían al "imperialismo populista", tan diferente del juego caballeresco de la política anterior. Estas lamentaciones elegíacas habían -de hecho- empezado mucho antes, hacia 1860 y a finales de siglo se habían transformado en un fuerte sentimiento de desorientación y de pérdida de misión. Vide, Sheeham, S. "german Liberalism in the nineteen Century, 1978. -Withe, Dans S. "National liberalism in the context of european polities", in the splintered Party, 1976.

7.- Pagano, R. "telematica e democrazia diretta", en I.A., 3.

8.- De Cabo, C. "La crisis del estado Social", ob. cit, especialmente el Capítulo dedicado al Estado Social y la periferia capitalista. -Vide Sonntag, M.R. "Hacia una teoría poítica del capitalismo periférico", Madrid 1977,. -J.A. Silva Michelena, "política y bloques de poder; crisis en el sistema mundial", 1984. -J. Petras, "Los estados periféricos: continuidad y cambio en la división del trabajo a escala mundial", en capitalismo, socialismo y crisis mundial", ob. cit.

9.- Laclau, "populist rupture and discourse", Screen Education", 1980.

10.- Offe, C. "Partidos políticos y nuevos movimientos sociales", Madrid 1988.

11.- Eulau, H. "Changing views of representation", en Eulau-Wahlke, 1978. Para Eulau, la incapacidad para dar respuesta teóricas a una realidad que, a pesar de ello, sigue funcionando, es lo que define las características de la crisis de representación política como una crisis "de la idea de representación política". (citado por Rodríguez Ibáñez), "de la crisis de legitimación al corporatismo", en R.C.E.C., 16, 1990.

12.- Loewenberg, G. "modern Parliaments: change or declin?", 1971.

13.- Labriola, S. "La crisis del Parlamento desde la óptica italiana", en Parlamento y Democracia.

14.- Por ahora, la crítica haberniana "insiste promordialmente en defender el mundo de la vida frente al mundo del sistema burocratizado, supuestamente imparcial y activado por los influjos únicos del poder y del dinero. Offe, por su parte, ha atemperado notablemente su radicalismo anticapitalista en su reciente obra "partidos políticos y nuevos movimientos sociales", donde se aboga por una alianza entre la socialdemocracia asistencial y los nuevos movimientos. También las posiciones mantenidas anteriormente por O'connor han sufrido una profunda revisión. O'connor señala que es necesario desprenderse de toda carga de las categorías marxistas tradicionales, legadas a través de las obras de Baran, Sweezy y G. Frank, que siguen dando primacía a los sujetos colectivos sobre los individuos concretos; según O'connor para entender las contradicciones del presente hay que entender y resolver antes las contradicciones de uno mismo. A partir de aquí estructura un discurso que, al decir de algunos críticos, se desliza peligrosamente hacia el subjetivismo personalista, en el que en modo alguno es un pensador original. Vide, Habermas, J. "Teoría de la acción comunicativa", v. II, M 1987, y "escritos políticos", Barcelona, 1988. -Offe, C. ob. cit., O'connor, "The meaning of crisis" Oxford, 1987. -Para un análisis crítico, Pico J. "Teorías sobre el Welfare State", Sistema, 1986.- Rodríguez Ibáñez, "legitimación y conflicto en las sociedades industriales avanzadas", 1987.

15.- Hennis, ob. cit.

16.- Pizzorno, A. "Il sistema pluralista di reppresentanza", 1985.

17.- García Pelayo, M. "Derecho Constitucional Comparado", Madrid, 1987.

18.- Vide Carré de Malberg, "Contribution...".

19.- Chatêlet, F. Pisier-Kouchner, "Las ideologías Políticas del siglo XX", Madrid 1986.

20.- Amato, G. "ob. cit.".

21.- De Vega, "El significado de la Representación Política", en R.E.P.

22.- García Pelayo, M. "transformaciones del Estado Contemporáneo", Madrid, 1986. 